\title{
Revisited the Critical Load Assessment of Huang et al. on Willems Tested Beck Column
}

\author{
Peter Praveen Jakkana ${ }^{*}$, Nageswara Rao Boggarapu ${ }^{2}$, Mahaboob Bodanapu ${ }^{1}$, \\ Appa Rao Bhogapurapu Venkata ${ }^{1}$, Narayana Cherukuri ${ }^{3}$ and Harnath Yeddala ${ }^{4}$ \\ ${ }^{1}$ Department of Mathematics, Koneru Lakshmaiah Education Foundation, Vaddeswaram, Guntur, 22502, India \\ ${ }^{2}$ Department of Mechanical Engineering, Koneru Lakshmaiah Education Foundation, Vaddeswaram, Guntur, \\ 522502, India \\ ${ }^{3}$ Department of Mathematics, Sri Harsha Institute of P.G Studies, Nellore, Andhra Pradesh, 524137, India \\ ${ }^{4}$ Department of Mathematics, Audhisankara College of Engineering, Gudur, Andhra Pradesh 524101, India
}

\begin{abstract}
Dynamic stability of elastic structures is a fascinating topic. Many researchers have examined the problem theoretically considering a cantilever column under a tip-concentrated tangential load, the so-called Beck column. Experimental verification is demanded since the critical load of Beck column is found to be approximately eight times to that of the classical Euler column. Different types of testing procedures are being adopted to create the follower force. Among them, notable Willems experimentation provides the critical load close to that of Beck column. Investigations made by other researchers indicate the controversy associated with modeling and testing of Willems on Beck column. Such an intriguing problem of structures loaded by non-conservative forces is revisited here through a simple mathematical formulation. This paper confirms the adequacy of Willems approach on Beck column and the wrong critical load assessment of others. It indicates the possibility on the practical realization of follower forces
\end{abstract}

\section{ARTICLE INFO}

\section{Article history:}

Received: 20 July 2020

Accepted: 28 September 2020

Published: 22 January 2021

DOI: https://doi.org/10.47836/pjst.29.1.14

E-mail addresses:

jppraveen17@kluniversity.in (Peter Praveen Jakkana)

bnrao52@rediffmail.com (Nageswara Rao Boggarapu) mahaboob@kluniversity.in (Mahaboob Bodanapu)

bvardr2010@kluniversity.in (Appa Rao Bhogapurapu Venkata)

nareva.nlr@gmail.com (Narayana Cherukuri)

yeddala@gmail.com (Harnath Yeddala)

* Corresponding author
Keywords: Beck column, coalescence frequency parameter, critical load parameter, dynamic stability, frequency parameter, tip-angle, tip-concentrated tangential load

\section{INTRODUCTION}

Space launch vehicles subjected to aerodynamic (drag) forces acting at the top and along the axis of the vehicle are modeled as columns under compressive 
loads. To assess their structural integrity, overall stability analysis will be performed for the flight conditions. After Beck in 1952, the problem of a cantilever column subjected to a follower load at its free-end has been solved adopting different techniques (Anderson \& Thomsen, 2002; Langthjem \& Sugiyama, 2000a; Langthjem \& Sugiyama, 2000b; Rao \& Rao, 1989a; Rao \& Rao, 1989b; Rao \& Rao, 1990; Rao \& Rao, 1991; Madhusudan et al., 2003; Zahharov et al., 2004; Kwasniewsi, 2010; Mutyalarao et al., 2012). Timoshenko and Gere (2012) had emphasized experimental verification on the critical load of Beck column. Sugiyama et al. (2000), Sugiyama (2002), and Sugiyama et al. (2019) had mounted a solid rocket motor at a free-end of the cantilever column for generating a tip-concentrated sub-tangential follower force and conducted experiments. They had demonstrated the stabilization of the system due to rocket thrust. However, their test results were found to be well below the critical load estimates (Mutyalarao et al., 2017). Tomski and Uzny (2013) had considered a slender system under a conservative load (in which the direction of force was towards the positive pole) and a non-conservative load (generating the Beck's load through a reaction engine), whose investigations were well documented in (Tomski et al., 1998; Tomski et al.,2007; Tomski \& Szmidia, 2004; Tomski \& Uzny, 2008; Tomski \& Uzny, 2010; Tomski \& Uzny, 2011). Willems (1966) had adopted a simple procedure to perform experiments. Though the critical load of Willems configuration was close to that of Beck's column, Huang et al. (1967) had presented theoretical analyses of Willems column and Beck column creating difference only in the fourth boundary condition. They recommended that Willems test results were not representing the Beck column. Augusti et al. (1967) had made discussion on the Willems experimental investigations. In his author's closure (Augusti et al., 1967), Willems accepted the difference in the treatment of Beck's problem and his experimentation. He claimed that his experimentation fulfilled the boundary conditions of the Beck's problem. Huang et al. (1967) had created a fourth boundary condition for the Willems column, which provided the same load versus frequency curve for the first mode of the Beck column, whereas for the second mode, the curve cut the load axis instead of coalescing with the first mode curve. Coincidentally, the second mode curve cut the load axis matched with the Willems test results. It should be noted that the fixed point of the column axis at a distance $\delta$ from the free end should be same only at the coalescence point, whereas it changed with the load parameter and the frequency parameter. Huang et al. (1967) had considered same $\delta$ value in the Willems column for the first and second modes. Due to this reason, the load versus frequency curve matched well with the first mode of the Beck column and differed drastically with the second mode. However, Huang et al. (1967) analysis results with fictitious fourth boundary condition for Willems column created great confusion for many researchers including Willems.

Elishakoff (2005a, 2005b) had stated that Willems experiment was "deposed". The load by the follower force directed towards the pole is not representing the Beck's force (Tomski et al., 1998; Tomski \& Uzny, 2008). Motivated by the work of the Willems (1966) 
and Huang et al. (1967), a simple mathematical formulation is presented here to resolve the controversy associated with the approach of Willems on applying tangential load to cantilever column at free end.

\section{MATHEMATICAL FORMULATION}

Figure 1 shows the deformation of a cantilever column subjected to a tip-concentrated follower load $(P)$ having tip-angle $\phi(0)$. 's' is the length of the deflection curve from the tip. $\phi(s)$ is the angle between the tangent to the deformed column and its vertical axis.

From the moment-curvature $\left(M-\rho^{-1}\right)$ relationship, Mutyalarao et al. (2017) have presented a system of nonlinear differential equations for large deflections of a cantilever column. They are briefly presented below as Equation 1, 2 and 3 for clarity.

$$
\frac{M}{E I}=\frac{1}{\rho}=\frac{d \phi}{d s}
$$

Here,

$$
M=M_{P}+M_{A}+M_{T}
$$

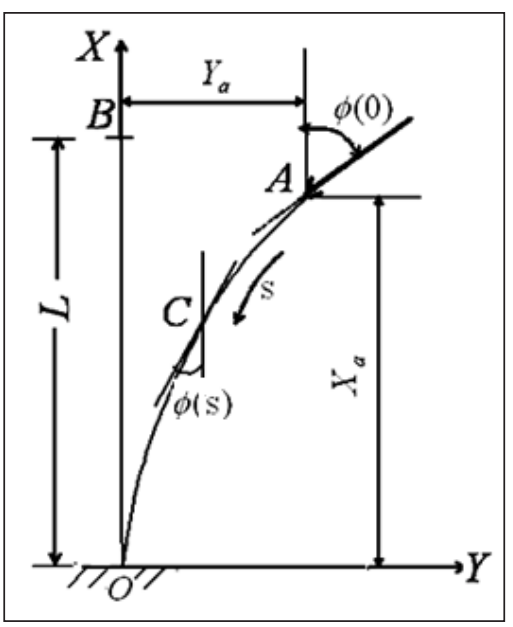

Figure 1. Deformation of a cantilever column subjected to a concentrated Follower load at its free-end (Mutyalarao et al., 2012; Mutyalarao et al., 2017)

The bending moment produced by the tangential load $\left(M_{P}\right)$, and by the action of inertia forces $\left(M_{A}, M_{T}\right)$ are as in Equation 3, 4 and 5

$$
\begin{aligned}
& M_{P}=-P \cos \phi(0) \times\left(Y_{a}-Y\right)+P \sin \phi(0) \times\left(X_{a}-X\right) \\
& M_{A}=\int_{0}^{S} m \ddot{u}\{Y(s, t)-Y(\zeta, t)\} d \zeta=-\Omega^{2} \int_{0}^{S} m\{Y(s, t)-Y(\zeta, t)\} d \zeta \\
& M_{T}=\int_{0}^{S} m \ddot{v}\{X(s, t)-X(\zeta, t)\} d \zeta=-\Omega^{2} \int_{0}^{S} m v\{X(s, t)-X(\zeta, t)\} d \zeta
\end{aligned}
$$

$E$ is the Young's modulus of the column material. $I$ is the moment of inertia. $L$ is the column length. $m$ is the mass per unit length of the column. $(u, v)=(X-L+s, Y)$, are the column deflections. $(X, Y)$ are the deformed column coordinates. Harmonic motion assumed for the deflections $(u, v)$ in Equation 4 and 5, which obey Equation 6 and 7 


$$
\begin{aligned}
& \ddot{u}+\Omega^{2} u=0 \\
& \ddot{v}+\Omega^{2} v=0
\end{aligned}
$$

$\Omega$ is the circular frequency and over dots denotes differentiation with respect to time, $t$. The deformed column coordinates can be obtained from

$$
(X, Y)=\int_{s}^{L}(\cos \phi, \sin \phi) d s \Rightarrow(x, y)=\left(\frac{X}{L}, \frac{Y}{L}\right)=\int_{\eta}^{1}(\cos \phi, \sin \phi) d \eta
$$

Here, $\eta=\frac{s}{L}$. At $s=0$, Equation 8 gives the column tip-coordinates $\left(X_{a}, Y_{a}\right)$.

Equation 1 and 8 are differentiated with respect to $s$. Defining; $H=\int^{\eta}(1-\xi-x) d \xi$ ; $V=\int_{0}^{\mu} y d \xi$; load parameter, $\lambda=\frac{P L^{2}}{E I}$; frequency parameter, $\omega=\Omega L^{2} \sqrt{\frac{m}{E I}}^{0}$, the governing equations are written in non-dimensional form as Equation 9, 10, 11, 12 and 13 (Mutyalarao et al., 2012; Mutyalarao et al., 2017)

$$
\begin{aligned}
& \phi^{\prime \prime}+\lambda \sin (\phi-\phi(0))+\omega^{2}(H \sin \phi+V \cos \phi)=0 \\
& H^{\prime}-(1-\eta-x)=0 \\
& V^{\prime}-y=0 \\
& x^{\prime}+\cos \phi=0 \\
& y^{\prime}+\sin \phi=0
\end{aligned}
$$

The boundary conditions for Equation 9 - 13 are as in Equation 14 and 15

$$
\begin{aligned}
& \phi=\phi(0), \phi^{\prime}=H=V=0 \text { at } \eta=0 \\
& \phi=x=y=0 \quad \eta=1
\end{aligned}
$$

Primes denote differentiation with respect to $\eta$. Following Willems (1966), the tangent at the free end of the deformed column in Figure 1 makes the angle $\phi(0)$, which can be related to Equation 16

$$
\tan \phi(0)=\frac{Y_{a}}{X_{a}-(L-\delta)}
$$


Here $\delta$ is the distance from the tip of the un-deformed column to the point where the tangent line at the free end of the deformed column intersects the column axis. In case of small deflections (i.e., $\phi \rightarrow 0$ ), $\cos \phi \approx 1$ and $\sin \phi \approx \phi$. Equation 8 gives $X(s)=L-s \Rightarrow X_{a}=L$ and Equation 16 becomes Equation 17

$$
\phi(0)=\frac{Y_{a}}{\delta} \Rightarrow \delta=\frac{Y_{a}}{\phi(0)} \quad \Rightarrow \frac{\delta}{L}=\frac{Y_{a}}{L \phi(0)}=\frac{y_{a}}{\phi(0)}
$$

Defining $\tilde{y}=\frac{y}{\phi(0)}$, the nonlinear differential Equation 9 - 15 for small deflections are in the form of Equation 18

$$
\tilde{y}^{i v}+\lambda \widetilde{y}^{\prime \prime}-\omega^{2} \tilde{y}=0
$$

The boundary conditions for Equation 18 arrived are as in Equation 19 and 20

$$
\begin{aligned}
& \widetilde{y}^{\prime}=-1, \widetilde{y}^{\prime \prime}=\widetilde{y}^{\prime \prime \prime}=0 \text { at } \eta=0 \\
& \widetilde{y}=\widetilde{y}^{\prime}=0 \text { at } \eta=1
\end{aligned}
$$

The general solution of the Equation 18 is Equation 21

$\tilde{y}(\eta)=A \cosh \left(\lambda_{1} \eta\right)+B \sinh \left(\lambda_{1} \eta\right)+C \cos \left(\lambda_{2} \eta\right)+D \sin \left(\lambda_{2} \eta\right)$

Here (Equation 22 and 23),

$$
\begin{aligned}
& \lambda_{1}=\sqrt{-0.5 \lambda+\sqrt{\omega^{2}+0.25 \lambda^{2}}} \\
& \lambda_{2}=\sqrt{0.5 \lambda+\sqrt{\omega^{2}+0.25 \lambda^{2}}}
\end{aligned}
$$

From Equation 19 and 21, one obtains Equation 24, 25 and 26

$$
\begin{aligned}
& \lambda_{1} B+\lambda_{2} D=-1 \\
& \lambda_{1}^{2} A-\lambda_{2}^{2} C=0 \Rightarrow C=\lambda_{1}^{2} \lambda_{2}^{-2} A \\
& \lambda_{1}^{3} B-\lambda_{2}^{3} D=0 \Rightarrow D=\lambda_{1}^{3} \lambda_{2}^{-3} B
\end{aligned}
$$

Using Equation 20, 21, 25 and 26 one obtains Equation 27 and 28 
$\left(\sinh \lambda_{1}-\lambda_{1} \lambda_{2}^{-1} \sin \lambda_{2}\right) A+\left(\cosh \lambda_{1}+\lambda_{1}^{2} \lambda_{2}^{-2} \cos \lambda_{2}\right) B=0$

$\left(\cosh \lambda_{1}+\lambda_{1}^{2} \lambda_{2}^{-2} \cos \lambda_{2}\right) A+\left(\sinh \lambda_{1}+\lambda_{1}^{3} \lambda_{2}^{-3} \sin \lambda_{2}\right) B=0$

From Equation 27 and 28, the transcendental equation relating $\lambda$ and $\omega$ is in the form $\left(\sinh \lambda_{1}-\lambda_{1} \lambda_{2}^{-1} \sin \lambda_{2}\right)\left(\sinh \lambda_{1}+\lambda_{1}^{3} \lambda_{2}^{-3} \sin \lambda_{2}\right)-\left(\cosh \lambda_{1}+\lambda_{1}^{2} \lambda_{2}^{-2} \cos \lambda_{2}\right)^{2}=0$, which can be further simplified to Equation 29

$\lambda^{2}+2 \omega^{2}\left(1+\cosh \lambda_{1} \cos \lambda_{2}\right)+\lambda \omega \sinh \lambda_{1} \sin \lambda_{2}=0$

Equation 29 is solved for $\omega$ by specifying $\lambda$ using the Mathematica ${ }^{\circledR}$.

Using Equation 24 - 28, one can find the arbitrary constants $A, B, C$ and $D$ in Equation 21. From Equation 17, one can find Equation 30

$$
\frac{\delta}{L}=\frac{y_{a}}{\phi(0)}=\frac{y(0)}{\phi(0)}=\widetilde{y}(0)=A+C=A\left(1+\lambda_{1}^{2} \lambda_{2}^{-2}\right)=\frac{\lambda_{2}^{3} \sinh \lambda_{1}+\lambda_{1}^{3} \sin \lambda_{2}}{\omega\left(\lambda_{2}^{2} \cosh \lambda_{1}+\lambda_{1}^{2} \cos \lambda_{2}\right)}
$$

Following Mutyalarao et al. (2017), stability of the column is assessed from $\lambda$ versus $\omega$ eigencurve. Critical load parameter $\left(\lambda_{c}\right)$ is a minimum value where the eigencurve cuts the $\lambda$-axis. The dynamic stability load is the minimum load where two branches of eigencurve coalesce. A simple procedure is presented below for generating the eigencurves from the first two frequency parameters $\left(\omega_{1}\right.$ and $\left.\omega_{2}\right)$ specifying the load parameter $(\lambda)$. Setting $\lambda=0$ in Equation 29, $\omega_{1}$ and $\left.\omega_{2}\right)$ are found for the unloaded column. The eigencurves are generated considering the first two frequencies by specifying the values of $\lambda$ varying from 0 in steps of 1 . When $\lambda$ value is reached to 21 , Mathematica ${ }^{\circledR}$ provides bifurcated frequency values. Each time, the step size is reduced to half for obtaining the frequency values prior to the bifurcation load parameter. At $\lambda_{c}=20.0509$, the two positive frequency values are tending to the coalescing frequency parameter $\left(\omega_{c}\right)$ value of 11.011. Variation of $\lambda$ with $\lambda$ is shown in Figure 2. Figure 3 shows variation of $\delta / L$ with $\lambda$. It should be noted that the results are presented in non-dimensional form for the non-dimensional load parameter $(\lambda)$ and frequency parameters $\left(\omega_{1}\right.$ and $\left.\omega_{2}\right)$ useful for any specified column dimensions and material.

For the specific $\lambda$, Figure 2 gives the first two frequency parameters $\left(\omega_{1}, \omega_{2}\right)$. Hence Figure 3 shows two $\delta / L$ values for each value of $\lambda$. At the coalescence frequency $\omega_{c}$ these two values of $\delta / L$ are identical. It is noted from Figure 3 that $\delta / L$ should be $0.42312 . \lambda$ versus $\omega$ curve shown in Figure 2 closely matches to that of Huang et al. (1967) for the Beck column. For the specific $\lambda$, the frequencies $\left(\omega_{1}\right.$ and $\left.\omega_{2}\right)$ and $\delta / L$ are obtained from 


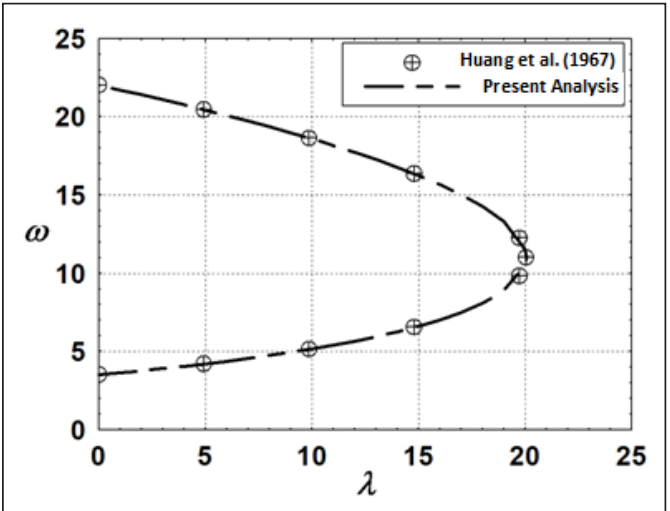

Figure 2. Variation of $\lambda$ with $\omega$

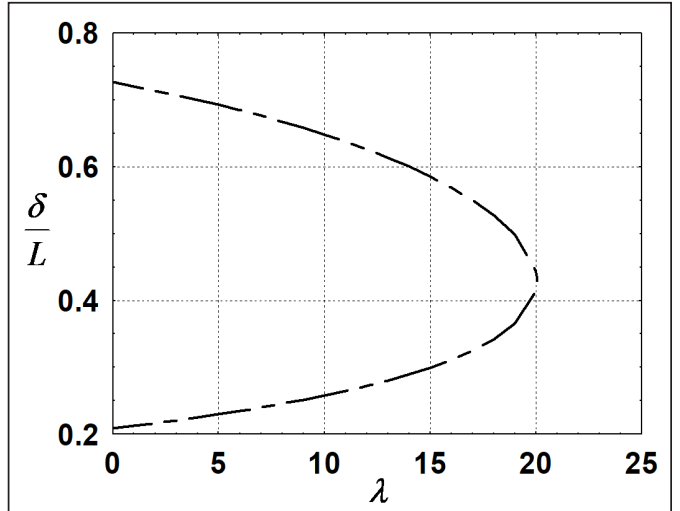

Figure 3. Variation of $\delta / L$ with $\lambda$

Equation 29 and 30. Table 1 gives the comparison of present analysis results with those of Willems (1966).

Values of $\delta$ for the specific $\lambda$ and $\omega_{l}$ in Table 1 are reasonably in good agreement with those of Willems (1966). However, the transcendental Equation 29 for the specific $\lambda$, gives slightly different $\omega_{1}$ and $\omega_{2}$. This is the reason why $\delta$ values of Willems (1966) in Table 1 slightly differ from the present analysis results. Figure 4 and 5 show the first and second mode shapes generated from Equation 21 for the unloaded column $(\lambda=0)$ and for the specific $\lambda$ and the corresponding $\omega_{1}$ and $\omega_{2}$. Figure 4 and 5 clearly indicate different mode shapes due to different frequencies $\left(\omega_{1}\right.$ and $\omega_{2}$ for the same load parameter $(\lambda)$. In case of critical load parameter $\left(\lambda_{c}\right)$, these two frequencies $\left(\omega_{1}\right.$ and $\left.\omega_{2}\right)$ tend to $\omega_{c}$. Hence, the first and second mode shapes in Figure 6 are identical, which result the same $\delta / L$.

Willems (1966) had used only the boundary conditions of the Beck column to arrive $\delta$ for the applied the load $(P)$. A slight impact was given to the column and observed vibrations of a stable character (when $P$ is less than the critical load) and damped out. Vibrations caused excessive amplitudes resulting in failure at the critical load. For the

Table 1

Comparison of frequencies $\left(\omega_{1}\right.$ and $\left.\omega_{2}\right)$ and $\delta$ for the specified $\lambda$

\begin{tabular}{|c|c|c|c|c|c|c|c|}
\hline \multirow{3}{*}{$\frac{\lambda}{\pi^{2}}$} & \multicolumn{4}{|c|}{ First Mode } & \multicolumn{3}{|c|}{ Second Mode } \\
\hline & \multirow[b]{2}{*}{$\lambda$} & \multirow[b]{2}{*}{$\omega_{1}$} & \multicolumn{2}{|c|}{$\delta / L$} & \multirow[b]{2}{*}{$\lambda$} & \multirow[b]{2}{*}{$\omega_{2}$} & $\delta / L$ \\
\hline & & & $\begin{array}{c}\text { Present } \\
\text { Analysis }\end{array}$ & Willems (1966) & & & $\begin{array}{c}\text { Present } \\
\text { Analysis }\end{array}$ \\
\hline 0 & 0 & 3.5160 & 0.7265 & 0.727 & 0 & 22.0344 & 0.2092 \\
\hline 0.5 & 4.9348 & 4.2071 & 0.6931 & 0.750 & 4.9348 & 20.4578 & 0.2296 \\
\hline 1.0 & 9.8696 & 5.1461 & 0.6496 & 0.676 & 9.8696 & 18.6395 & 0.2570 \\
\hline 1.5 & 14.8044 & 6.5545 & 0.5884 & 0.585 & 14.8044 & 16.3664 & 0.2977 \\
\hline 2.0 & 19.7392 & 9.8282 & 0.4665 & 0.464 & 19.7392 & 12.2545 & 0.3936 \\
\hline 2.0315 & 20.0509 & 11.01 & 0.4252 & ----- & 20.0509 & 11.01 & 0.4252 \\
\hline
\end{tabular}




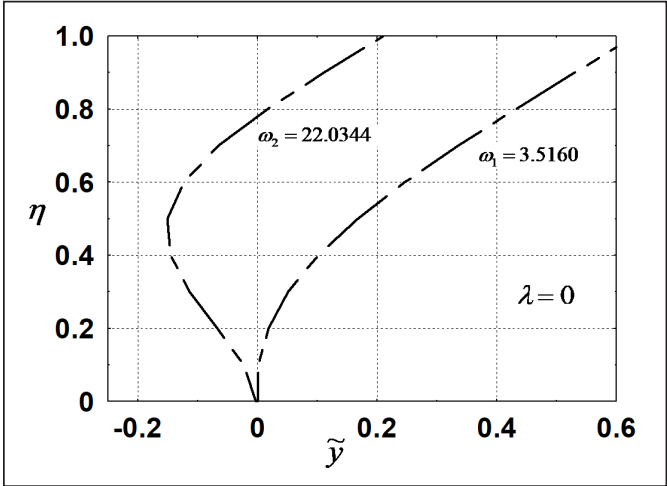

Figure 4. Mode shapes for the unloaded cantilever column

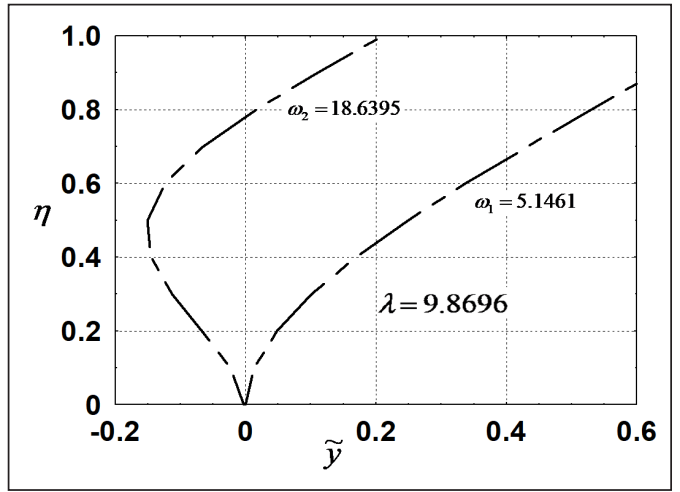

Figure 5. Mode shapes for the loaded cantilever column

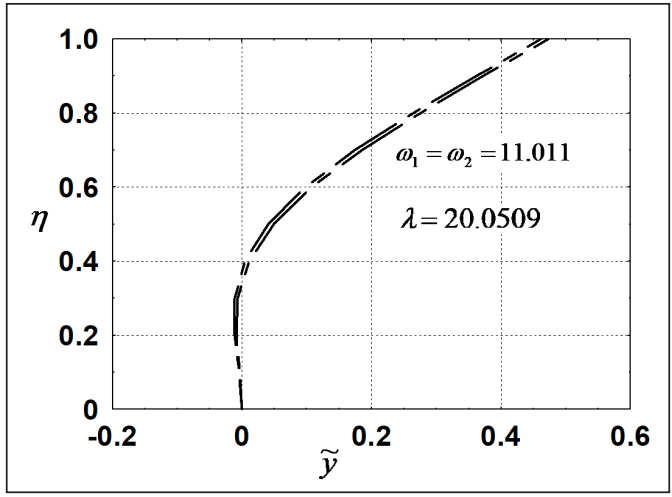

Figure 6. Mode shapes for the critically loaded cantilever column

steel column of size $304.8 \times 7.62 \times 2.54 \mathrm{~mm}$, the critical load parameter reported by Willems (1966) was 18.61, whereas the present analysis was 20.05. The discrepancy in the results might be due to inaccurate calculations of $\delta$ by Willems (1966), mass and stiffness of the column. However, Willems (1966) experimental results are within $7 \%$ of the analysis results. It should be noted from Willems (1966) that Willems had concentrated on the critical load alone. The fast camera might had been used to capture the individual displacement stages of column during flutter phenomena. The eigencurve of the first frequency obtained by Willems (1966) and that of the Beck column were same. The upper curve of $\delta$ in Figure 3 corresponds to $\lambda$ and $\omega_{1}$, whereas the lower curve of $\delta$ corresponds to $\lambda$ and $\omega_{2}$. For the case of $\lambda_{c}$ and $\omega_{c}, \delta$ value is $0.423 L$. By imposing correctly, the passage through this fixed point yield $\lambda_{c}$.

The curvilinear coordinate system simplifies the complexity of the mathematical formulation for large deflections. The above small deflection analysis results are obtained by specifying the tip-angle $\phi(0)$ as $0.01^{\circ}$ and solving Equation $9-15$. Being a non-linear 
nature of the problem, it has to be solved numerically. As in Mutyalarao et al. (2013), the post-critical load parameter $\left(\lambda_{c}\right)$, coalesce frequency parameter $\omega_{c}$, and the tip-coordinates of the Beck column as in Equation 31:

$$
\left(x_{a}, y_{a}\right)=\left(\frac{X}{L}, \frac{Y_{a}}{L}\right)
$$

for different values of the tip-angle $\phi(0)$ are evaluated numerically by solving the nonlinear differential Equation 9 - 15 using the fourth-order Runge-Kutta integration scheme. The boundary value problem is converted to an initial value problem adopting shooting method. For large deflection analysis, Equation 16 can be written as Equation 32

$$
\tan \phi(0)=y_{a}\left\{x_{a}-1+\frac{\delta}{L}\right\}^{-1}
$$

which implies as in Equation 33

$$
\frac{\delta}{L}=\frac{y_{a}}{\tan \phi(0)}-x_{a}+1
$$

Using Equation 33, $\delta$ is computed and values are presented in Table 2. It is noted that $\delta$ increases marginally with increasing the tip-angle $\phi(0)$. From the above observations, one can conclude that Willems has considered in his experimentation only the Beck column.

Table 2

Post-critical load parameter $\left(\lambda_{c}\right)$ for the specific tip-angle, $\phi(0)$

\begin{tabular}{cccccc}
\hline$\phi(0)($ degree $)$ & $\lambda_{c}$ & $\omega_{c}$ & $x_{a}$ & $y_{a}$ & $\begin{array}{c}\delta / L \\
\text { Eq. }(33)\end{array}$ \\
\hline 10 & 20.1888 & 11.0294 & 0.9944 & 0.0747 & 0.4292 \\
20 & 20.1623 & 11.0634 & 0.9776 & 0.1484 & 0.4301 \\
30 & 21.3529 & 11.1211 & 0.9499 & 0.2201 & 0.4313 \\
40 & 22.4690 & 11.2269 & 0.9117 & 0.2887 & 0.4323 \\
50 & 24.0584 & 11.3828 & 0.8636 & 0.3534 & 0.4329 \\
60 & 26.2815 & 11.6238 & 0.8062 & 0.4128 & 0.4321 \\
\hline
\end{tabular}

\section{CONCLUSION}

Dynamic stability of elastic structures is a fascinating topic, which is being examined theoretically by many researchers considering a cantilever column under a tip-concentrated tangential load. The load versus frequency curve is essential for assessing the dynamic stability of such columns. Timoshenko and Gere (2012) had emphasized experimental validation since the critical load was found to be approximately eight times to that of the 
classical Euler column. Different types of testing procedures are followed to create the follower force. Among them, notable Willems (1966) experimentation provided the critical load close to that of Beck column. But, Huang et al. (1967) had specified wrong input in the analysis and drawn wrong conclusions on Willems experimentation, which had created great confusion for many researchers including Willems in 1966 (Augusti et al., 1967).

This paper resolves the controversy associated with the Willems experiments on the stability of Beck column through a simple mathematical modeling. It should be noted that Willems (1966) had aimed only on the critical load of the column and demonstrated its value close to that of the Beck column. Use of the fast camera in Willems experimentation might have captured the individual displacement stages of column during flutter phenomena. Large deflection analysis results indicate marginal increase in $\delta$ with increasing the tip-angle $\phi(0)$. Equation 16 can be used to obtain the position of the point of intersection corresponding to the critical load for small as well as large deflections of the cantilever column subjected to a tip-concentrated follower load.

The controversial articles of Koiter (1996) and Sugiyama et al. (1998) on unrealistic and realistic follower forces remains a matter of debate (Mascolo, 2019). The problem in such cases is in the practical realization of follower forces (Bolotin, 1963; Elishakoff, 2005b). Mullagulov (1994) had successfully created follower forces and performed tests. Approaches of Willems (1966) and Mullagulov (1994) confirmed the demands of Koiter (1996) on experimental validation of Beck column for the practical realization of follower forces.

\section{ACKNOWLEDGEMENT}

The authors are grateful to the reviewers for their constructive criticism to improve the clarity of presenting the work in the paper and the journal for encouragement.

\section{REFERENCES}

Anderson, S. B., \& Thomsen, J. J. (2002). Post-critical behavior of Beck's column with a tip mass. International Journal of Nonlinear Mechanics, 37(1), 135-151. doi: https://doi.org/10.1016/S0020-7462(00)00102-5

Augusti, G., Roorda, J., Herrmann, G., \& Levinson, M. (1967). Discussion: Experimental verification of the dynamic stability of a tangentially cantilever column. Transactions of ASME Journal of Applied Mechanics, 34(2), 523-524. doi: https://doi.org/10.1115/1.3607729

Bolotin, V. V. (1963). Non-conservative problems of the theory of elastic stability. New York, NY: Macmillan.

Elishakoff, I. (2005a). Essay on the contributors to the elastic stability theory. Meccanica, 40(1), 75-110. doi: https://doi.org/10.1007/s11012-004-2199-y

Elishakoff, I. (2005b). Controversy associated with the so-called 'Follower Forces': Critical overview. Applied Mechanics Reviews, 58(2), 117-142. doi: https://doi.org/10.1115/1.1849170 
Huang, N. C., Nachabar, W., \& Nemat-Nasser, S. (1967). On Willems' experimental verification of the critical load in Beck's problem. Transactions of ASME Journal of Applied Mechanics, 34(1), 243-245. doi: https:// doi.org/10.1115/1.3607646

Koiter, W. T. (1996). Unrealistic follower forces. Journal of Sound and Vibration, 194(4), 636-638. doi: https:// doi.org/10.1006/jsvi.1996.0383

Kwasniewski, L. (2010). Numerical verification of post-critical Beck's column behavior. International Journal of Nonlinear Mechanics, 45(3), 242-255. doi: https://doi.org/10.1016/j.ijnonlinmec.2009.11.007

Langthjem, M. A., \& Sugiyama, Y. (2000a). Optimum design of cantilevered columns under the combined action of conservative and non-conservative loads, Part-I: The undamped case. Computers and Structures, 74(4), 385-398. doi: https://doi.org/10.1016/S0045-7949(99)00050-4

Langthjem, M. A., \& Sugiyama, Y. (2000b). Dynamic stability of columns subjected to follower loads: A survey. Journal of Sound and Vibration, 238(5), 809-851. doi: https://doi.org/10.1006/jsvi.2000.3137

Mascolo, I. (2019). Recent developments in the dynamic stability of elastic structures. Frontiers in Applied Mathematics and Statistics, 5, 1-16. doi: 10.3389/fams.2019.00051.

Madhusudan, B. P., Rajeev, V. R., \& Rao, B. N. (2003). Post-buckling of cantilever columns having variable cross-section under a combined load. International Journal of Non-Linear Mechanics, 38(10), 1513-1522. doi: https://doi.org/10.1016/S0020-7462(02)00086-0

Mutyalarao, M., Bharathi, D., \& Rao, B. N. (2012). Dynamic stability of cantilever columns under a tipconcentrated sub tangential follower force. Mathematics and Mechanics of Solids, 18(5), 449-463. doi: https://doi.org/10.1177/1081286512442436

Mutyalarao, M., Bharathi, D., Narayana, K. L., \& Rao, B. N. (2017). How valid are Sugiyama’s experiments on follower forces? International Journal of Non-linear Mechanics, 93, 122-125. doi: https://doi. org/10.1016/j.ijnonlinmec.2014.12.007

Mullagulov, M. K. (1994). Experimental-theoretical study of the stability of rods, compressed by follower forces. Strength of Materials, 26(6), 441-446. doi: https://doi.org/10.1007/BF02209415

Rao, B. N., \& Rao, G. V. (1989a). Post-critical behaviour of a uniform cantilever column under a tip concentrated follower force. Journal of Sound and Vibration, 132(2), 350-352.

Rao, B. N., \& Rao, G. V. (1989b). Some studies on buckling and post- buckling of cantilever columns subjected to conservative or non-conservative loads. The Journal of the Aeronautical Society of India, 41(2), 165-182.

Rao, B. N., \& Rao, G. V. (1990). Stability of tapered cantilever columns subjected to a tip concentrated sub tangential follower force. Forschung Im Ingenieurwesen, 56(3), 93-96.

Rao, B. N., \& Rao, G. V. (1991). Post-critical behaviour of a tapered cantilever column subjected to a tipconcentrated follower force. Journal of Applied Mathematics and Mechanics, 71(11), 471-473. doi: https:// doi.org/10.1002/zamm.19910711116

Sugiyama, Y., Langthjem, M. A., \& Ryu, B. J. (1998). Realistic follower forces. Journal of Sound and Vibration, 225(4), 779-782. 
Peter Praveen Jakkana, Nageswara Rao Boggarapu, Mahaboob Bodanapu, Appa Rao Bhogapurapu Venkata, Narayana Cherukuri and Harnath Yeddala

Sugiyama, Y., Katayama, K., \& Kiriyama, K. (2000). Experimental verification of dynamic stability of vertical cantilever columns subjected to a sub-tangential force. Journal of Sound and Vibration, 236(2),193-207. doi: https://doi.org/10.1006/jsvi.1999.2969

Sugiyama, Y. (2002). Experimental approach to non-conservative stability problems. In A. P. Seyranian \& I. Elishakoff (Eds.), Modern problems of structural Stability (pp. 341-394). Vienna, Austria: Springer. doi: 10.1007/978-3-7091-2560-1

Sugiyama, Y., Langthjem, M. A., \& Katayama, K. (2019). Dynamic stability of columns under non-conservative forces: Theory and experiments. Cham, Switzerland: Springer International Publishing. doi: 10.1007/9783-030-00572-6

Timoshenko, S. P., \& Gere, J. M. (2012). Theory of elastic stability. New Delhi, India: Tata Mc Graw-Hill Education Private Limited.

Tomski, L., Przybylski, J., Gołebiowska-Rozanow, M., \& Szmidla, J. (1998). Vibration and stability of a cantilever column subject to a follower force passing through a fixed point. Journal of Sound and Vibration, 214(1), 67-81. doi: https://doi.org/10.1006/jsvi.1998.1528

Tomski, L., \& Szmidla, J. (2004). Theoretical and experimental investigations of the natural vibrations of the divergence and divergence pseudoflutter type systems. In PAMM: Proceedings in Applied Mathematics and Mechanics (Vol. 4, No. 1, pp. 418-419). Berlin, Germany: WILEY-VCH Verlag.

Tomski, L., Szmidla, J., \& Uzny, S. (2007). The local and global instability and vibration of systems subjected to non-conservative loading. Thin-Walled Structures, 45(10-11), 945-949. doi: https://doi.org/10.1016/j. tws.2007.08.019

Tomski, L., \& Uzny, S. (2008). Free vibrations and the stability of a geometrically non-linear column loaded by a follower force directed towards the positive pole. International Journal of Solids and Structures, 45(1), 87-112. doi: https://doi.org/10.1016/j.ijsolstr.2007.07.011

Tomski, L., \& Uzny, S. (2010). Chosen slender systems in aspect of possibility of specific load realization. Vibrations in Physical Systems, 24, 429-434.

Tomski, L., \& Uzny, S. (2011). The regions of flutter and divergence instability of a column subjected to Beck's generalized load, taking into account the torsional flexibility of the loaded end of the column. Mechanics Research Communications, 38(2), 95-100. doi: https://doi.org/10.1016/j.mechrescom.2011.01.013

Tomski, L., \& Uzny, S. (2013). Free vibrations and stability of a new slender system subjected to a conservative or nonconservative load. Journal of Engineering Mechanics, 139(8), 1133-1148. doi: https://doi. org/10.1061/(ASCE)EM.1943-7889.0000463

Willems, N. (1966). Experimental verification of the dynamic stability of a tangentially loaded cantilever column. Transactions of ASME Journal of Applied Mechanics, 33(2), 460-461. doi: https://doi. org/10.1115/1.3625073

Zakharov, Y. V., Okhotkin, K. G., \& Skorobogatov, A. D. (2004). Bending of bars under a follower load. Journal of Applied Mechanics and Technical Physics, 45(5), 756-763. doi: https://doi.org/10.1023/ B:JAMT.0000037975.91152.01 